\section{Fragmentos de uma genealogia do trabalho em saúde: a genealogia como ferramenta de pesquisa}

\author{
Fragments of a health work genealogy: \\ genealogy as a research technique
}

\author{
1 Programa de Pós-graduação \\ em Psicologia Social \\ e Institucional, \\ Universidade Federal \\ do Rio Grande do Sul, \\ Porto Alegre, Brasil. \\ Correspondência \\ H. C. Nardi \\ Programa de Pós-graduação \\ em Psicologia Social \\ e Institucional, Universidade \\ Federal do Rio Grande \\ do Sul. Rua Ramiro Barcelos \\ 2600, Sala 13, Térreo, \\ Porto Alegre, RS \\ 90035-003, Brasil. \\ hcnardi@aol.com
}

\begin{abstract}
The article aims to explore the influence of health work in subjectification processes. The notion of history commonly used in health-related scientific output is based on an evolutionist and developmental logic. As a counterpoint, the genealogical approach used in this article and based on Michel Foucault highlights the notions of discontinuity, event, and the production of truth as tools to rethink the ethical and political implications involved in the production of knowledge, practices, and subjects. To illustrate these aspects we sketch a health work genealogy, specifically in the field of mental health and HIVIAIDS work.
\end{abstract}

Genealogy; Health Personnel; Mental Health
Henrique Caetano Nardi 1

Jaqueline Tittoni 1

Letícia Giannechini 1

Tatiana Ramminger 1

\section{A noção de história na perspectiva genealógica}

Muitos autores 1,2,3 diferenciam, na perspectiva de Foucault, dois métodos distintos, uma "arqueologia do saber" e uma "genealogia do poder", os quais teriam diferentes formas e objetos de análise. Nesse sentido, os primeiros livros de Foucault estariam interessados em determinar como se formam diferentes discursos e saberes - a psiquiatria, a medicina e as ciências humanas na perspectiva arqueológica; enquanto seus últimos escritos, principalmente os três volumes da História da Sexualidade, são frutos de um trabalho genealógico. No entanto, outros pesquisadores, como Gros 4 e o próprio autor, afirmam que sua obra sempre buscou uma "genealogia do sujeito". Nesta construção, Foucault 5 considerou três modos de objetivação que transformam os seres humanos em sujeitos: a objetivação do sujeito no discurso; a objetivação do sujeito nas práticas divisoras, que dividem o sujeito no seu interior e em relação aos outros: o louco e o são, o doente e o sadio, os criminosos e os bons; e, finalmente, o modo pelo qual o ser humano reconhece-se como sujeito (subjetivação).

Em relação à genealogia, uma das definições de Foucault 1 é entendê-la como a possibilidade de constituir um saber histórico das lutas, ativando os saberes locais, descontínuos, desqualificados e não legitimados, contra os efei- 
tos de poder centralizadores ligados à instituição de um único discurso. O discurso científico, por exemplo, cumpre este papel na atualidade, ordenando e hierarquizando os demais saberes em nome de um conhecimento "mais" verdadeiro e legítimo que os outros.

O autor entendia a História como identificada com esse ideal de cientificidade, caracterizando-a como uma disciplina que tem se ocupado em registrar a "verdade" dos fatos, o que "realmente" aconteceu em períodos passados. Ao contrário, a intenção da pesquisa genealógica é produzir rupturas na lógica da linearidade, do desenvolvimento e da comensurabilidade que marca(ra)m a racionalidade científica moderna, começando pelo questionamento do que é a "verdade" 1.

Para os gregos, na Antigüidade, a questão filosófica - como ter acesso à verdade? - e a prática da espiritualidade - que transformações são necessárias em si mesmo para ter acesso à verdade? - são questões que pertencem ao mesmo registro e que não podem ser tratadas em separado. Já o modelo cartesiano postula que a ciência é a única forma de acesso à verdade, não havendo mais a necessidade de transformar-se para merecê-la 6 .

Na análise genealógica, o conhecimento é “invenção" e a verdade, assim como o sujeito, é uma construção histórica. Em contrapartida, a ambição da ciência na modernidade, incluindo a História, é produzir um saber capaz de revelar a essência e a origem das coisas, tomando o sujeito e o objeto como previamente constituídos e o conhecimento como natural e universal, posto que o objetivo da ciência é descobrir a verdade.

O que Foucault nos ensina é que a verdade é produzida, reafirmando que cada época determina o que pode ser dito e pensado a partir dos "jogos de verdade". Os jogos de verdade se referem ao conjunto de regras de produção da verdade, ou ainda, aos diferentes procedimentos que conduzem a uma verdade - um "regime de verdades", que sustenta uma determinada forma de dominação 7. Como definição, Foucault 1 (p. 13) propõe que: "por verdade não quero dizer 'o conjunto das coisas verdadeiras a descobrir ou a fazer aceitar', mas o 'conjunto das regras segundo as quais se distingue o verdadeiro do falso e se atribui ao verdadeiro efeitos específicos de poder"'. Nesta definição também fica claro o entendimento do autor de que existe uma perpétua articulação entre o poder e o saber. A própria idéia de que um regime de verdades é fruto dos jogos, ou seja, da luta entre diferentes campos de saber, pressupõe um tensionamento constante. A constituição de um cam- po de saber nunca é neutra, ao contrário sempre produz e insere-se em relações de poder, tal como entendidas por Foucault 8 (p. 727): “as relações de poder não são algo de mal em si mesmas, das quais devemos nos livrar, eu creio que não existem sociedades sem relações de poder, se nós as entendermos como estratégias pelas quais os indivíduos tentam se conduzir, de determinar a conduta dos outros. O problema, portanto, não é de tentar dissolver as relações de poder em uma utopia de uma comunicação completamente transparente, mas fornecer regras de direito, técnicas de gestão e a moral, o ethos, as práticas de si, que permitirão, nos jogos de poder, de jogar com um mínimo possível de dominação".

Sendo assim, as relações de poder não têm efeito meramente repressivo, como se impedissem ou bloqueassem os campos de saber. $\mathrm{O}$ poder, longe de impedir o saber, o produz. Foucault 5 afirma que a análise das relações de poder se dá pela via do estudo do antagonismo das estratégias, que pressupõe a compreensão das formas de resistência frente às diferentes formas de dominação. Para o autor, as relações de poder somente se estabelecem entre "homens livres", configurando relações de incitação recíproca e de luta, trata-se de "agonismo" mais do que de "antagonismo". Assim podemos pensar que a genealogia estuda como se constroem as possibilidades de emergência dos discursos/saberes (no caso aqui estudado da AIDS e da saúde mental) em determinados jogos de dominação e resistência, que configuram a legitimidade da verdade para cada período.

Foucault 1 afirma que a genealogia não se opõe à História, mas à pesquisa de origem. No principal artigo em que se ocupa deste tema Nietzsche, a Genealogia e a História - evidencia o esforço de Nietzsche em negar a pesquisa da origem, substituindo o termo Ursprung (origem) por outros - Entestehung/Herkunft - que embora sejam ordinariamente também traduzidos como “origem", são um esforço lingüístico para desfazer essa idéia.

O primeiro termo - Entestehung - está ligado à idéia de proveniência, de herança: “...mas não nos enganemos; essa herança não é uma aquisição, um bem que se acumula e se solidifica: é antes um conjunto de falhas, de fissuras, de camadas heterogêneas que a tornam instável (...). A pesquisa da proveniência não funda, muito pelo contrário: ela agita o que se percebia imóvel, ela fragmenta o que se pensava unido; ela mostra a heterogeneidade do que se imaginava em conformidade consigo mesmo" 1 (p. 21).

Além da descontinuidade, a genealogia, como análise da proveniência, diz respeito à ma- 
neira como os acontecimentos históricos se inscrevem no corpo, sendo ela o ponto de articulação entre o corpo e a história. "Ela deve mostrar o corpo inteiramente marcado de história e a história arruinando o corpo" 1 (p. 22).

Já o segundo termo utilizado por Nietzsche - Herkunft - está ligado à idéia de ponto de surgimento, de emergência, de aparecimento de algo, fruto de uma luta de forças. "O que se encontra no começo histórico das coisas não é a identidade ainda preservada da origem - é a discórdia entre as coisas, é o disparate" 1 (p. 18). Isto demonstra o quanto a história é composta por campos de lutas, combates, imposições de sentidos e modos de subjetivação. Ao mesmo tempo, problematiza “certos recortes ou agrupamentos que já nos são familiares” 1 (p. 24), desnaturalizando sentidos já fixados e cristalizados, e apontando que há possibilidade de invenção e transformação desses sentidos.

Enquanto a proveniência designa a marca do acontecimento no corpo, a emergência designa um lugar de afrontamento. A genealogia em contraponto à atividade histórica tradicional coloca a proveniência no lugar da origem; o acaso da luta no lugar da linearidade e da continuidade.

Pensar "historicamente e fisiologicamente" como diria Nietzsche, marcando a semelhança dos ideais da História e da Medicina, é buscar a verdade e a totalidade, como se existisse uma única história, aquela que realmente vale 1 . A crítica de Nietzsche ao historiador é que ele procura apagar seu ponto de vista como se o mesmo não existisse, como se não tivesse crenças nem tampouco fizesse escolhas. Seu trabalho sustenta-se na ilusão do dever de tudo compreender sem distinção, sem fazer diferença. Nada lhe deve escapar, nada deve ser excluído.

O genealogista, ao contrário, sabe que o sentido histórico depende da perspectiva - “é um olhar que sabe tanto de onde olha quanto o que olha" 1 (p. 30). Entendendo que não existem origens e nem verdades a desvelar, mas apenas interpretações, a genealogia é a história destas interpretações.

Foucault deu preferência, em suas pesquisas, aos documentos "esquecidos" pela história, pergaminhos embaralhados e empoeirados, mas que diziam muito a respeito das lutas travadas para que determinado saber fosse ou não vencedor, adquirindo ou não legitimidade social. Seu trabalho sobre o arquivo não busca uma verdade última. Sua análise procura estabelecer as relações que unem os diferentes documentos que compõem o arquivo e que não são simplesmente catalogados por uma organização serial, mas pela função desempenhada em estruturas sociais marcadas pelas condições políticas de possibilidades dos discursos, ou seja, os jogos de poder e saber que legitimam em cada época e em cada contexto um discurso como verdadeiro.

\section{Fragmentos de uma genealogia do trabalho em saúde mental e na prevenção do HIV/AIDS}

Ao propormos uma análise genealógica, buscamos entender as condições de possibilidade para a produção de uma subjetividade (no caso, do trabalhador da saúde), marcada por diferentes verdades que orientam práticas e formas de se inserir no mundo. As investigações de Foucault 5 que, em princípio, parecem debruçar-se sobre assuntos díspares, têm um eixo central: compreender "como nos tornamos sujeitos" em cada tempo e em cada contexto 9 . Inspirados nessa construção, buscamos delimitar os regimes de verdade que balizam os processos de subjetivação dos trabalhadores da saúde em dois campos específicos: AIDS e saúde mental.

A partir do momento em que a doença não é mais objeto do cuidado dos familiares, passando a ter pessoas que se ocupam exclusivamente desta tarefa, o cuidado em saúde ganha o status de um trabalho configurado com base em "um conjunto de práticas discursivas e não discursivas que se encarrega de instituir o sujeito do qual fala" 10 (p. 24). Esta afirmação parte do entendimento de que os discursos não são subjetivos, mas sim subjetivam, na medida em que o indivíduo toma para si determinado discurso, considerado legítimo e verdadeiro, modificando-se e identificando as prerrogativas deste discurso como suas. Sendo assim, os diferentes discursos que sustentaram o cuidado em saúde, incidiram sobre a vida dos trabalhadores, determinando não só o seu modo de trabalhar, mas também a experiência que fazem de si mesmos.

\section{Saúde mental}

Para entendermos o(s) discurso(s) que for$\mathrm{ja}(\mathrm{m})$, atualmente, o trabalho e o trabalhador de saúde mental, temos de retomar as verdades que sustentaram, em diferentes épocas, o cuidado com a loucura no Brasil. A importância de acompanhar este percurso é entender o princípio organizador desta experiência, ou seja, buscar uma genealogia do presente.

E quem é aquele que hoje se denomina trabalhador da saúde mental? Entendemos que o 
trabalhador da saúde mental constitui-se no confronto do discurso da Reforma Psiquiátrica com o discurso médico psiquiátrico, o qual, durante muito tempo, possuía a legitimidade absoluta em relação ao cuidado com a loucura.

A psiquiatria naturalizou a idéia de que a loucura é um tema para especialistas e que há um lugar específico para o tratamento do louco: o manicômio. Foucault 11 questionou firmemente esta premissa, afirmando que não é natural que a loucura fosse considerada uma doença, mais especificamente, uma doença mental, tampouco é evidente que seu destino fosse o manicômio. Esta foi uma "verdade" como tantas outras, construída historicamente e que, pouco a pouco, vai ruindo em suas certezas frente a outros discursos, inicialmente minoritários, mas que a duras penas adquiriram legitimidade social.

Para sustentar essa afirmação - de que a doença mental é uma categoria historicamente construída - podemos fazer um recorte em relação ao tratamento destinado ao louco no Brasil Colonial. Naquela época, os “loucos" ficavam perambulando pelas ruas das cidades brasileiras, quando muito eram recolhidos às Santas Casas de Misericórdia ou Cadeias Públicas. Nos hospitais não existia a previsão de nenhum tipo de tratamento específico, sendo que aos loucos eram destinados celas insalubres e castigos corporais. Cabe lembrar que a função do hospital também era bem distinta da atual, já que seu objetivo principal não era o cuidado em saúde, e sim a assistência aos pobres, sobretudo aqueles que vão morrer. O hospital era um lugar para morrer - um morredouro. Quem assistia aos doentes eram religiosos ou leigos que não estavam ali para realizar a cura do doente, mas para garantir sua própria salvação. “ $A s$ segurava-se, portanto, a salvação da alma do pobre no momento da morte e a salvação do pessoal hospitalar que cuidava dos pobres" 1 (p. 102).

O louco, como o doente pobre, deveria ser afastado da sociedade, ao mesmo tempo em que necessitava de assistência. $\mathrm{O}$ discurso religioso, predominante à época do Brasil Colonial e no Império, era um poderoso dispositivo de controle que se associava a um modo de subjetivação no qual o "cuidador" e aquele que é cuidado eram subjetivados simultaneamente; um buscando sua própria salvação espiritual e o outro, sendo fixado na posição do coitado, do perigoso e do inútil para o trabalho, que deve ser afastado do convívio social. Não havia uma preocupação com a cura, mas uma condenação da ociosidade 11 .

O cuidado prestado não era considerado trabalho e tampouco se justificava no discurso científico, ainda incipiente naquele momento. Um cuidado que apesar de revestido pelo manto da caridade - como uma forma de expiar pecados e assegurar a salvação eterna - cumpria com a função social de controle daqueles que poderiam ou não fazer parte da sociedade do trabalho que daria seus primeiros passos a partir da abolição da escravatura e da proclamação da República. Quando a medicina se organiza como discurso legitimado socialmente, o hospital adquire outro caráter, passando a ser considerado um instrumento terapêutico, de cura. O médico, antes mero coadjuvante, torna-se o principal responsável pela organização hospitalar. Vários autores 1,12,13,14 dão conta deste embate travado nos hospitais gerais e, posteriormente, também nos psiquiátricos, entre os religiosos - que insistiam em permanecer no comando administrativo e diário das instituições hospitalares; e os médicos - que, aos poucos, ancorados no discurso científico, chamaram para si toda a responsabilidade (e controle) não só dos hospitais, mas também de tudo que diz respeito à saúde das populações.

A genealogia desse processo no contexto europeu parte do "grande internamento" 11 . Naquele momento, internavam-se (encarceravam) no mesmo espaço e sem discriminação alguma, os velhos, os enfermos, as crianças, as pessoas que não queriam ou não podiam trabalhar, os homossexuais, os doentes mentais etc. A imagem utilizada por Foucault para ilustrar a passagem para a "criação do asilo" é a libertação dos loucos por Pinel, demarcando a afirmação da legitimidade da medicina para classificar as doenças e os comportamentos como normais ou desviantes. Assim, e com o auxílio dos outros dispositivos disciplinares (o Direito e a Pedagogia, por exemplo), criam-se as distinções: os doentes mentais, no asilo; os jovens, em estabelecimentos de educação; os delinqüentes, na prisão 11.

A loucura passa a ser identificada como doença mental quando Pinel, enquanto portador do discurso nascente da psiquiatria como ciência, começa a defender que a loucura seria um desarranjo das funções mentais, notadamente as intelectuais. Seguindo a perspectiva de Descartes - que instituiu a racionalidade como único modo possível de pensamento e de acesso à verdade - Pinel entendia que a loucura separava o homem de sua própria verdade, posto que agia diretamente sobre a razão. O homem, na loucura, é um estranho em relação a si mesmo - um alienado de sua verdade, que só poderá lhe ser restituída pela mão do médico. Por conseqüência, é o discurso médico psiquiátrico que detém a verdade sobre a loucura, 
e não o contrário. Ninguém pode dizer-se ou reconhecer-se louco, mas ser diagnosticado como tal 11 .

O que afastava o homem de sua razão era um tipo de imoralidade, excesso ou desvio, passível de cura por um "tratamento moral", sendo necessário um lugar específico e o afastamento do convívio social para esta reeducação. Mesmo sob a égide da Revolução Francesa não havia problema moral em se propor o isolamento do louco, posto que liberdade e razão tinham o mesmo limite: quando a razão fosse atingida, a liberdade poderia ser coagida. A internação não mais objetivava enclausurar o louco, mas tornava-se instrumento necessário para sua cura, ou seja, não é apenas uma necessidade da sociedade, mas também do próprio louco 15.

No Brasil não foi diferente 16 e, a partir de meados do século XIX, grupos de higienistas começam a defender a construção de hospícios, apoiados no discurso médico. O primeiro hospital psiquiátrico do Brasil e da América Latina é inaugurado em 1852, no Rio de Janeiro, o Hospício D. Pedro II. Vários estados brasileiros seguiram pelo mesmo caminho. No Rio Grande do Sul, em um processo minuciosamente descrito por Wadi 14, o Hospício São Pedro é inaugurado em 29 de junho de 1884, resultado de uma luta de mais de uma década dos filantropos da Santa Casa. No entanto, se num primeiro momento, médicos e filantropos andaram de mãos dadas para retirar os loucos dos hospitais gerais, "rapidamente os primeiros passaram a reivindicar maior espaço nas decisões relativas aos alienados. Do término da construção do prédio do Hospício à sua administração, da definição da doença mental à sua cura, tudo deveria estar submetido ao olhar e à ação do médico" 14 (p. 121).

O tratamento moral, tal qual preconizado por Pinel, tinha dois princípios básicos: o da disciplina e o do isolamento, o que exigia uma organização espacial específica, assim como pessoas que cumprissem o papel da vigilância. Dois personagens começam a se destacar no cuidado do "alienado mental": o médico psiquiatra e o enfermeiro psiquiátrico. O primeiro, como diria Esquirol 14 (p. 174), é “o princípio da vida de um hospital de alienados; a ele compete dirigir todas as ações, porque ele deve ser o regulador de todos os pensamentos". O segundo, "colocado em último lugar na escala hierárquica - e sofrendo, ele mesmo, a vigilância dos que o antecedem nesta escala - era aquele que exercia prioritariamente a função de vigilante, devendo acompanhar os doentes em todos os lugares e em todos os momentos" 13 (p. 436).
Em 1912, a psiquiatria ganha o status de especialidade médica autônoma, coincidindo com um aumento significativo do número de estabelecimentos destinados aos doentes mentais. O manicômio e a psiquiatria fortalecem-se e alimentam-se mutuamente, ganhando cada vez mais espaço. Na década de 1950 foram sintetizados e introduzidos, como forma de tratamento, os primeiros neurolépticos no Brasil. A descoberta dos novos medicamentos, no entanto, não reduziu o número das internações psiquiátricas, ao contrário, estas se intensificaram com a privatização dos equipamentos sociais, sobretudo a partir do Golpe Militar de 196417.

Com as reflexões sobre as conseqüências dos regimes totalitários na Europa, após a Segunda Guerra Mundial, assistimos a uma ampla mobilização em prol de ideais libertários e humanistas. Discussões sobre cidadania, ampliação dos direitos humanos e liberdade disseminaram-se por todo mundo. Os discursos totalitários, as verdades absolutas, a naturalização das condições de miséria e segregação das populações, são problematizadas, contextualizadas e questionadas em seus efeitos.

Nascem o Movimento Institucional na França, as Comunidades Terapêuticas na Inglaterra, o Movimento da Antipsiquiatria e a Desospitalização nos Estados Unidos 18. Cada um, com suas particularidades e diferenças, pretendia questionar e modificar o tratamento e, conseqüentemente, o modo de trabalhar com a doença mental. A Desinstitucionalização Italiana, em particular, radicalizou esta proposta, sem defender a reciclagem, modernização ou humanização do manicômio, mas sim sua extinção, entendendo que todas as instituições que seguem seu modelo e as lógicas que justificam sua existência são incompatíveis com uma política de respeito aos direitos humanos.

Uma polifonia de saberes desafia, cada vez com maior força, a aparente estabilidade do discurso médico. Este, mesmo que ainda dominante, definitivamente não é mais o único que pode falar sobre a loucura, o louco e seu cuidado.

No Brasil, essas tendências ganham corpo, ao final da década de 1970 , com a criação do Movimento dos Trabalhadores de Saúde Mental 16, que se mobilizou não só por mudanças no tratamento psiquiátrico, mas também pela reforma sanitária e pela redemocratização política do país. Neste movimento, há referência explícita a um "trabalhador de saúde mental", para além do médico e do enfermeiro, e que se subjetiva no embate dos discursos presentes no bojo da luta antimanicomial. 
$\mathrm{Na}$ década seguinte, essa iniciativa toma força, ampliando-se em vários sentidos. Usuários e familiares juntam-se aos trabalhadores, dispostos a implicar toda sociedade no questionamento da segregação da loucura. Tal como nos aponta Amarante 19, a Reforma Psiquiátrica é um processo complexo no qual se articulam quatro dimensões simultâneas: a dimensão epistemológica, que diz respeito a uma reconstrução teórica nas áreas da saúde mental e da psiquiatria; a dimensão da assistência, que chama à invenção de novos dispositivos de assistência e cuidado; a dimensão jurídico-política com a revisão da legislação civil, penal e sanitária, abrangendo e garantindo direitos civis, sociais e humanos; e, finalmente, a dimensão cultural, que inclui um conjunto mais amplo de iniciativas para a transformação do imaginário social sobre a loucura.

Podemos concluir, assim, que o trabalhador da saúde mental, se constrói, hoje, na tensão dos discursos que refletem o embate interno ao campo da saúde mental - a qual defende um deslocamento do saber médico-psiquiátrico para a interdisciplinaridade, da noção de doença para a de saúde, dos muros dos hospitais psiquiátricos para a circulação pela cidade, do doente mental para o portador de sofrimento psíquico, do incapaz tutelado para o cidadão. O trabalho em saúde mental deveria incluir, portanto, não apenas o conhecimento técnico-científico, mas também a implicação política e afetiva com a construção de um outro modo de cuidar e entender a loucura.

Entretanto, embora o discurso da reforma psiquiátrica tenha adquirido certa legitimidade, ainda é forte a penetração de um discurso médico-psiquiátrico identificado com o modelo manicomial. Em nossa experiência acompanhando a implantação da reforma psiquiátrica em um antigo hospital psiquiátrico, pudemos perceber como a exigência de um outro tipo de cuidado com o usuário encobria a problematização das relações de poder/saber no trabalho. O saber do trabalhador parecia nada valer, fazia parte de um outro tempo que tinha de ser esquecido, como fica evidente na fala de uma auxiliar de enfermagem, em um grupo de supervisão: "eu entrei aqui e não sabia nada. Aprendi com meus colegas. Trabalho assim há vinte anos e sempre deu certo. Agora vocês chegam aqui e dizem que está tudo errado? Que tem que mudar tudo?".

Não é incomum, ainda, encontrar serviços de saúde mental que mais parecem minimanicômios, assim como hospitais psiquiátricos que se valem do discurso da reforma psiquiátrica como verniz para encobrir velhas práti- cas. Estar atento a este jogo entre diferentes discursos que nos atravessam enquanto trabalhadores, pesquisadores e cidadãos, constitui o fazer genealógico proposto por Foucault.

\section{Prevenção ao vírus do HIV/AIDS}

O trabalho em prevenção à HIV/AIDS, embora seja mais recente - delimita-se o início da epidemia entre o fim dos anos 1970 e o início dos anos 1980 - caracteriza-se inicialmente por uma lógica que remonta às campanhas sanitaristas do início do século.

A saúde pública tem como base a medicina moderna do final do século XVIII que, sob o véu da cientificidade, legitimou a crescente medicalização do espaço social, ancorada na polícia médica e na medicina social ${ }^{13}$. Sua principal estratégia é combater as epidemias e endemias, esquadrinhando e controlando o espaço urbano com dispositivos sanitários, produzindo saberes vinculados à idéia de higiene pública. Passa-se então, a investir na vida, e não na morte, na lógica do biopoder, ou seja, do controle das populações. A biopolítica, por meio dos poderes locais, se ocupará, assim, da gestão da saúde, da higiene, da alimentação, da sexualidade e da natalidade, entre outros, na medida em que estes temas são tratados como responsabilidade do Estado 9 .

A perspectiva higienista no Brasil, caracterizada pela Liga Brasileira de Higiene Mental fundada em 1923, iniciou com a idéia de aperfeiçoar a assistência aos doentes. Porém, a partir de 1926, os projetos passaram a visar à prevenção na perspectiva da eugenia e da educação moral dos indivíduos: "o alvo de cuidados psiquiátricos passou a ser o indivíduo normal e não o doente" 20 (p. 28). O que interessava era a prevenção pela via da normalização dos comportamentos e não da cura.

O princípio da eugenia - "termo inventado pelo fisiologista Galton para designar o estudo dos fatores socialmente controláveis que podem elevar ou rebaixar as qualidades raciais das gerações futuras, tanto física quanto mentalmente" 20 (p. 30) - tinha por objetivo preservar a raça, que se buscava afastar os chamados "anormais" da possibilidade de reprodução. A forma encontrada foi a de "prescrever e esterilizar alienados delinqüentes, degenerados alcoólicos inveterados, quer como penalidade, quer como prophylactico" 20 (p. 36).

No caso da AIDS, também foi em nome da ciência que se legitimaram práticas de marginalização de diferentes segmentos sociais, presentes na idéia dos grupos de risco, que marcaram o início da epidemia. Esse enfoque, cons- 
truído pela perspectiva epidemiológica, formatou uma tecnologia do sexo ordenada "em torno da instituição médica, da exigência de normalidade e, ao invés da questão da morte e do castigo eterno, o problema da vida e da doença" 9 (p. 111). Ou seja, passa-se a investir na sexualidade "ao mesmo tempo, como objeto de análise e alvo de intervenção" 9 (p. 29).

Essa perspectiva revestiu moralmente a epidemia da AIDS, onde a tradução dos aspectos morais construídos socialmente vinculava a AIDS a grupos de risco, considerados ora como vítimas (os hemofílicos), ora como culpados (homossexuais, prostitutas e usuários de drogas) 21. Podemos evocar os ideais eugenistas para entendermos como estas classificações foram produzindo uma divisão entre as práticas e formas de exercício da sexualidade consideradas como normais, as desviantes: "os mais fortes deveriam sobreviver; os mais fracos desaparecer. A tarefa principal do eugenista consistia em evitar os desvios dessa evolução natural da espécie, provocados pelas ações culturais de certos indivíduos ou grupos sociais" 20 (p. 41).

A classificação de "grupos de risco" produziu uma objetivação dos sujeitos a partir de comportamentos considerados desviantes. Assim, as políticas de prevenção buscavam não só incentivar o cuidado nas relações sexuais (uso de preservativo), como também modificar comportamentos, por meio da diminuição do número de parceiros e/ou a definição de um único parceiro ou até mesmo a abstinência sexual. A estratégia direcionava-se para a prescrição de determinados modos de experimentar a vida sexual de forma a inscrevê-la nos códigos morais vigentes, os quais não colocavam em questão discussões polêmicas como a fragilidade do casamento monogâmico, de um ideal de família e das tramas da fidelidade/infidelidade.

Ainda assim - e como Butler 22 demonstra, ao afirmar que a reinstalação das estratégias de (bio)poder nunca se dão sem um deslizamento que abre novas possibilidades de resistência e criação - a epidemia da AIDS iluminou diversas questões relacionadas à sexualidade, trazendo-as para o espaço público, sobretudo, em um primeiro momento, pela pressão do movimento gay, algo que, até então, deveria ser mantido no espaço privado. Apesar disso, o controle da epidemia continuou a ser tratado como algo primordialmente da esfera do indivíduo.

É no tensionamento entre esses diferentes discursos que se produzem os trabalhadores do cuidado/prevenção à AIDS. Em uma primeira resposta aos movimentos sociais, passou-se a falar de comportamento de risco. " $A$ vantagem desse tipo de aproximação é que a partir dele não há mais qualquer grupo particular que detenha o peso e a tarefa de haver-se com a epidemia" 23 (p. 414). Esta noção introduz toda a população como "alvo" da infecção e coloca que ela se dá a partir de um comportamento arriscado, exercido por um indivíduo.

Esse enfoque, no entanto, continuou restringindo a epidemia a decisões individuais, portanto, sem levar em conta os modos de subjetivação que produzem determinadas formas de ser homem, mulher, heterossexual, bissexual, homossexual, trans ou outra forma de classificação. Esta perspectiva "não encara de frente o fato de que os comportamentos de risco serão sempre fruto dos contextos e relações em que os indivíduos estão imersos, determinando chances diferentes de serem atingidos e de se defender do problema" 23 (p. 415).

Parker 24 (p. 103) afirma o quanto, na década de 1990, houve esforços para superar essa dicotomia, “deslocando-nos da noção de risco individual para uma nova percepção de vulnerabilidade social”. Esta noção é fundamental já que enfoca a necessidade de uma capacitação coletiva e mobilização comunitária como elementos cruciais na resposta à epidemia, visando a entender o risco baseando-se em um contexto mais amplo de relações e condições sociais.

Ayres 23 define três âmbitos dessa vulnerabilidade, que se inter-relacionam: individual, social e programático. No plano individual, a vulnerabilidade está associada à exposição individual às situações que possibilitam a infecção. Porém, estas situações devem ser entendidas com base no conhecimento que os indivíduos têm sobre a epidemia e a possibilidade de transformarem esta condição frente a ela, e não baseando-se numa "decorrência imediata e exclusiva da vontade das pessoas” 23 (p. 417). A vulnerabilidade social deve ser entendida a partir de um espectro mais amplo e em função de condições coletivas, em que deve ser levado em conta o acesso à informação, os recursos investidos na saúde, bem como o acesso a esses serviços, aspectos sócio-políticos e culturais, maior ou menor possibilidade de participação nas decisões de seu interesse, e condições sociais básicas (como moradia, escola etc.). O âmbito da vulnerabilidade programática refere-se ao desenvolvimento de ações de saúde especificamente voltadas para o problema da AIDS, e pode ser entendida por aspectos como o compromisso do Estado em solucionar o problema, por meio do planejamento de ações destinadas para tal, bem como o gerenciamento, manutenção, investimentos e avaliação das ações e programas envolvidos. 
Em função dessas questões mais amplas, incluídas nos discursos atuais de prevenção à AIDS, entendemos que o trabalho nesse campo perpassa relações consigo e com os outros, por intermédio dos diversos discursos sobre HIV/AIDS presentes no cotidiano dos trabalhadores. Os discursos, portanto, conformam as práticas e constituem esses trabalhadores. Esta relação consigo pode produzir a reflexão sobre a vulnerabilidade, tanto do trabalhador como da população atendida. Desta forma, poderemos, como sugerem Sweat \& Dennison (1995, apud Parker 24, p. 106): “...ultrapassar campanhas de informação, educação e comunicação para garantir diversas formas de mudança estrutural e promover estratégias capacitadoras destinadas a dotar mais adequadamente as comunidades vulneráveis com os instrumentos necessários para lidar com sua própria vulnerabilidade".

Assim, a produção de homogeneidade e da igualdade presente nos discursos epidemiológicos, por exemplo, passam a ser questionados, de forma a possibilitar a criação de práticas reflexivas que comportem diferentes modos de viver e trabalhar. Como ilustra Parker 24 (p. 110), o desafio do trabalho em prevenção à AIDS é o de "perceber nossa luta contra a AIDS como parte de um projeto muito mais amplo de transformação social".

\section{A genealogia como ferramenta de pesquisa}

Neste ensaio buscamos pensar como se configuram os campos de conflito e as condições políticas que marcam a emergência dos discursos/verdades que sustentam os processos de subjetivação dos trabalhadores da prevenção à AIDS e da saúde mental. A genealogia, como ferramenta de pesquisa, permite compreender como a ciência que surge no momento cartesiano - caracterizada pela separação sujeito do conhecimento/sujeito da experiência - sustentou práticas divisórias que, sob o manto da neutralidade, invisibilizaram um determinado código moral que as produziram.

A eugenia, por exemplo, uma vez forjada no campo científico, definiu grupos desviantes como doentes e a sua extinção como tratamento necessário, afirmando um ideal de homogeneidade e de exclusão da diferença. Aqui, já se vislumbra a confluência dos dispositivos de normalização dos comportamentos que marcaram tanto o trabalho em saúde mental na formação da psiquiatria no Brasil como o início do trabalho na prevenção do HIV/AIDS.
Retomando as diferenças de método anunciadas na primeira parte deste artigo, enquanto uma história linear e cumulativa evidenciaria as transformações do saber científico e das práticas terapêuticas, a genealogia visibiliza o caráter moral e político ligado às práticas em saúde. Permite, assim, desnaturalizar pressupostos importantes do discurso médico hegemônico e explicitar continuidades e rupturas não lineares presentes nas lutas do campo da saúde. Da mesma forma, coloca em questão a racionalidade como fundamento central do trabalho, ao demonstrar que o trabalhador se envolve com a "moralidade" no exercício de suas atividades, possibilitando, por exemplo, rupturas na lógica clássica da organização do trabalho que separa concepção e execução.

A genealogia evidencia as rupturas nas práticas de controle das populações a partir dos deslocamentos que reintroduzem a dimensão da experiência na discussão dos rumos da produção do conhecimento e na orientação das práticas em saúde. A dimensão da experiência remete para a sensibilidade dos familiares, trabalhadores e usuários, tanto no campo da saúde mental como do HIV/AIDS, os quais se insurgiram contra o sofrimento produzido pelas diferentes formas de exclusão. Esta experiência produz, para além da moral, uma dimensão ética, entendida como prática reflexiva da liberdade 8 , que possibilita a emergência dos saberes minoritários, constituindo a base dos movimentos sociais que lutam para transformar as práticas nestes campos.

Tomando a dimensão ética como base das rupturas, podemos compreender por que, apesar das transformações internas à saúde mental e à prevenção do HIV/AIDS se originarem de movimentos sociais, encontramos diferentes configurações das relações de poder nestes campos. A reforma psiquiátrica surge de um movimento dos trabalhadores da saúde mental, que inicialmente questionam as práticas institucionais e a racionalidade científica, mas posteriormente se vêm amarrados a elas na implantação da reforma. Já as transformações da forma de condução dos programas de prevenção ao HIV/AIDS partem das discussões do Movimento GLS, questionando diretamente o caráter moral das ações e mantendo-se na posição de pressão política. Como efeito, temos o fortalecimento do programa de prevenção à AIDS como política pública, enquanto a saúde mental permanece fortemente atrelada à vontade política dos diferentes governos.

Ao compreender que as práticas em saúde são forjadas com base em práticas divisórias, a genealogia constitui-se em importante ferra- 
menta para a produção do conhecimento em saúde. Todo saber é político. É neste sentido que Foucault 8 sugere que a ética seja pensada como a forma privilegiada de reflexão sobre as maneiras de viver. Ele afirma que o sentido de sua obra é mostrar às pessoas que elas podem ser muito mais livres do que pensam. E isso é possível na medida em que evidenciamos, por meio da genealogia, que o sujeito ético se constitui mediante práticas historicamente construídas em cada cultura. Esta perspectiva de produção do conhecimento e de análise das práticas, permite construir políticas de saúde que busquem aumentar a liberdade nos jogos de poder e verdade que demarcam o campo da saúde e do trabalho em saúde.

\section{Resumo}

O artigo busca explorar os processos de subjetivação a partir do dispositivo do trabalho, especificamente do trabalho em saúde. Parte do entendimento de que a noção de história utilizada em muitas das produções em saúde está calcada em uma lógica evolucionista e desenvolvimentista. Em contrapartida, a perspectiva da genealogia utilizada neste artigo e baseada em Foucault, dá visibilidade às noções de descontinuidade, acontecimento e produção de verdades, trazendo em si condições para repensarmos as implicações éticas e políticas da produção de conhecimento, práticas e sujeitos. Para ilustrarmos estas questões, esboçaremos uma genealogia do trabalho em saúde, mais especificamente em relação à produção dos trabalhadores da saúde mental e aos trabalhadores da prevenção à infecção pelo HIVIAIDS.

Genealogia; Pessoal de Saúde

\section{Colaboradores}

T. Ramminger e L. Giannechini efetuaram a revisão bibliográfica sobre o tema da genealogia em Foucault. T. Ramminger teceu considerações a respeito do trabalho em saúde mental e L. Giannechini sobre o trabalho na prevenção do HIV/AIDS. H. C. Nardi e J. Tittoni revisaram o artigo, elaborando a versão final, bem como sua conclusão.

\section{Agradecimentos}

Ao Conselho Nacional de Desenvolvimento Científico e Tecnológico (CNPq) pelo auxílio financeiro para o projeto de pesquisa. 


\section{Referências}

1. Foucault M. Microfísica do poder. Rio de Janeiro: Graal; 1999.

2. Billouet P. Foucault. Paris: Les Belles Lettres; 1999.

3. Ortega F. Amizade e estética da existência em Foucault. Rio de Janeiro: Graal; 1999.

4. Gros F. Le courage de la verité. Paris: PUF; 2002.

5. Foucault M. O sujeito e o poder. In: Dreyfus H, Rabinow P, organizadores. Michel Foucault: uma trajetória filosófica: para além do estruturalismo e da hermenêutica. Rio de Janeiro: Forense Universitária; 1995. p. 231-49.

6. Foucault M. Estética, ética y hermenéutica. Barcelona: Editorial Paidós; 1999. (Obras Esenciales, v. III).

7. Nardi HC. Trabalho e ética: os processos de subjetivação de duas gerações de trabalhadores metalúrgicos e do setor informal (1970-1999) [Tese de Doutorado]. Porto Alegre: Programa de Pósgraduação em Sociologia, Universidade Federal do Rio Grande do Sul; 2002.

8. Foucault M. Dits et écrits. Paris: Gallimard; 1994.

9. Foucault M. História da sexualidade I: a vontade de saber. Rio de Janeiro: Graal; 2001.

10. Bernardes AG. Subjetivação de trabalhadores da saúde mental: "a humanização dos pacientes será a nossa humanização" [Dissertação de Mestrado]. Porto Alegre: Pontifícia Universidade Católica do Rio Grande do Sul; 2002.

11. Foucault M. Historie de la folie à l'âge classique. Paris: Gallimard; 1972.

12. Castel R. A ordem psiquiátrica: a idade de ouro do alienismo. Rio de Janeiro: Graal; 1978.

13. Machado R, organizador. Danação da norma: medicina social e constituição da psiquiatria no Brasil. Rio de Janeiro: Graal; 1978.
14. Wadi YM. Palácio para guardar doidos: uma história das lutas pela construção do hospital de alienados e da psiquiatria no Rio Grande do Sul. Porto Alegre: Editora da UFRGS; 2002.

15. Pessotti I. O século dos manicômios. Rio de Janeiro: Editora 34; 1996.

16. Amarante $P$, organizador. Loucos pela vida: a trajetória da reforma psiquiátrica no Brasil. Rio de Janeiro: Panorama/Escola Nacional de Saúde Pública, Fundação Oswaldo Cruz; 1995.

17. Cerqueira L. Psiquiatria social: problemas brasileiros de saúde mental. Rio de Janeiro: Editora Atheneu; 1984.

18. Desviat M. A reforma psiquiátrica. Rio de Janeiro: Editora Fiocruz; 1999.

19. Amarante P. Reforma psiquiátrica. In: Textos da mostra inaugural "Memória da Loucura". Rio de Janeiro: Centro Cultural de Saúde. http://www. cdsm.ufes.br/arquivos.html (acessado em Out/ 2002).

20. Costa JF. História da psiquiatria no Brasil. Rio de Janeiro: Campus; 1980.

21. Paiva V, organizador. Em tempos de AIDS. São Paulo: Summus; 1992.

22. Butler J. The psychic life of power. Stanford: Stanford University Press; 1997.

23. Ayres JRCM. Vulnerabilidade dos jovens ao HIV/ AIDS: a escola e a construção de uma resposta social. In: Silva LH, organizador. A escola cidadã no contexto da globalização. Petrópolis: Editora Vozes; 1998.

24. Parker R. Na contramão da AIDS. Rio de Janeiro: Associação Brasileira Interdisciplinar de AIDS; 2000.

Recebido em 28/Jul/2004

Versão final reapresentada em 07/Dez/2004

Aprovado em 18/Fev/2005 